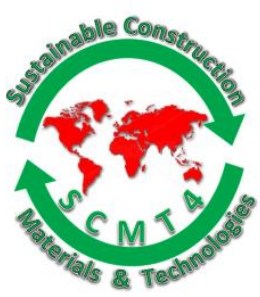

SCMT4

Las Vegas, USA, August 7-11, 2016

\title{
Cement-Based Materials with Wastes from Demolished Buildings
}

\author{
Niyazi Ugur Kockal ${ }^{1}$ \\ ${ }^{1}$ Akdeniz University, Department of Civil Engineering, 07058, Antalya, Turkey \\ Email:<ukockal@yahoo.com>.
}

\begin{abstract}
In this paper, an effective procedure of response surface methodology (RSM) has been utilized for finding the optimal values of input parameters describing the construction waste $(\mathrm{CW})$ type and content which were considered also as design variables in the cementitious materials (CM). Physical, mechanical and elastic properties have been regarded as performance characteristics. The proposed mathematical models suggested described the performance indicators within the limits of the factors being investigated. Then, the optimal production combination that would maximize strength and modulus of elasticity was found while keeping the density minimum. The largest desirability value was obtained by ceramic aggregate with nearly $30 \%$ of replacement ratio.
\end{abstract}

\section{INTRODUCTION}

Most previous studies investigated the effect of individual factor such as waste type, waste content and particle size of raw materials on the performance of CM. However, the interaction effect of various factors on the performance of mortars and/or concretes was not usually considered. Response surface methodology comprises a group of statistical techniques for model building and model exploitation [Azargohar and Dalai 2005; Mannan et al. 2007; Muthukumar et al. 2003]. By careful design and analysis of experiments, it seeks to relate a response or output variable to the levels of a number of predictors or input variables that affect it. The classical approach of changing one variable at a time and studying the effect of the variable on the response is a complicated technique, particularly in a multivariate system or if more than one response are of importance [Muthukumar et al. 2003]. Design of experiments are statistical techniques which can be used for optimizing such multivariable systems. Engineers often wish to determine the values of the process input parameters at which the responses reach their optimum [Benyounis et al. 2008]. Design Expert software was also used for analysis of the test results in other studies which had different research areas [Dhiman and Verma 2012; Garg et al. 2014; Kohli and Singh 2010; Mugendiran et al. 2014; Ramakrishna and Susmita 2012]. The optimum could be either a minimum or a maximum of a particular function in terms of the process input parameters. RSM is a set of mathematical and statistical techniques that are useful for modelling and predicting the response of interest affected by a number of input variables with the aim of optimizing this response. RSM also specifies the relationships among one or more measured responses and the essential controllable input factors. 
To optimize the response " $y$ ", it is necessary to find an appropriate approximation for the true functional relationship between the independent variables and the response surface. Usually a second-order polynomial Equation is used in RSM [Benyounis et al. 2008; Liyana-Pathirana and Shahidi 2005; Muthukumar et al. 2003].

$y=b_{0}+\Sigma b_{i} x_{i}+\Sigma b_{i i} x_{i i}^{2}+\Sigma b_{i j} x_{i} x_{j}+\varepsilon$

where

$\mathrm{y}=$ response function,

$\mathrm{b}=$ coefficient,

$\mathrm{x}=$ factor,

$\varepsilon=$ error

$b_{0}, b_{i}, b_{i i}$, and $b_{i j}$ are the regression coefficients for intercept, linear, quadratic and interaction terms, respectively, and $\mathrm{x}_{\mathrm{i}}$, and $\mathrm{x}_{\mathrm{j}}$ are the independent variables.

Since time and money are involved while performing the experimental runs, it is pertinent to reduce the number of runs while not compromising the desired goals [Kohli and Singh 2011]. Using design of experiments based on response surface methodology, the CM having minimum density and maximum strength and stiffness can be arrived with minimum number of experiments without the need for studying all possible combinations experimentally. Further the input levels of the different variables for a particular level of response can also be determined. With recent advances in construction materials industry, using wastes as aggregate and/or binder in CM, namely concrete and mortar, is becoming a reality and opening the door to evaluating CW in CM especially which can be obtained from the rubbles of most demolished constructions due to the inevitable result of urban transformation projects. Despite the abundance of mostly suitable wastes for manufacturing CM, access to information about these materials is still limited. Relevant persons such as designers, manufacturers and implementers need more tools to capture their ideas as models with graded compositions and to convert these models into application for their production. The overall goal of this study is to identify the inputs and provide the requisite solutions by researching methods to represent, design and process these models with promoting the use of these by a wider audience of designers and researchers.

\section{EXPERIMENTAL INVESTIGATION}

Materials and method. The experimental data used in this study for optimisation work were taken from previous investigation [Kockal 2015]. CM specimens were cast using CEM II/A-M (P-L) 42,5N complying with TS EN 197-1, CW (brick, marble and ceramic), superplasticizer, water, natural sand with a water/cement ratio of 0.50 .

The close passing percentages were selected for aggregates and similar consistencies were achieved for fresh mixtures to eliminate the effects of grading and workability differences on CM properties. Natural crushed sand was replaced with waste aggregates in a ratio of $30 \%$ and $60 \%$. All substitutions were made in volume. All sample preparations were processed in a similar manner, according to TS EN 196-1.

The bulk density values were obtained by testing $100 \mathrm{~mm}$ cube specimens according to ASTM C 642. The flexural and compressive strength of hardened mortar specimens were determined in accordance with TS EN 1015-11. Also, $\varnothing 50 \times 100 \mathrm{~mm}$ cylindrical specimens were tested to obtain compressive strength and modulus of elasticity according to ASTM C 39 and ASTM C 469, respectively.

In this study, waste type and their content were selected as variables and the properties (density, compressive strength and flexural strength) of CM were chosen as response variables. Design-Expert software was used to design experiment and to analyze the experimental data. The models between variables and response values were established. Then, the interaction effects of variables on the properties of CM 
were also discussed, as well as Design-Expert software was used to optimize the technical parameters. Historical data design with two factors and three levels was used to fit suitable response surface models by software. The factors and experimental design were given in Table 1.

Table 1. Input Parameters with Their Values

\begin{tabular}{|l|l|l|l|l|l|l|l|l|l|l|}
\hline Factors & Specimen & 1 & 2 & 3 & 4 & 5 & 6 & 7 & 8 & 9 \\
\hline A & Waste content (\%) & 0 & 30 & 60 & 0 & 30 & 60 & 0 & 30 & 60 \\
\hline B & Waste type & Brick & & & & & & & & \\
& & & & & & & & & \\
\end{tabular}

\section{RESULTS AND DISCUSSIONS}

Using software, the experimentally obtained density, compressive and flexural strength values were analyzed and the coefficients of the parameters were arrived at and given by the regression equation. According to the obtained results the developed models are statistically accurate and can be used for further analysis. The final equations in terms of coded factors are shown below:

$$
\begin{aligned}
\text { Density }= & +2.00-0.055 * \mathrm{~A}-0.048 * \mathrm{~B}[1]+0.032 * \mathrm{~B}[2]-0.050 * \mathrm{AB}[1] \\
& +0.035 * \mathrm{AB}[2]+0.032 * \mathrm{~A}^{2}
\end{aligned}
$$

Compressive Strength $=+41.77-1.83 * \mathrm{~A}-1.70 * \mathrm{~B}[1]+0.27 * \mathrm{~B}[2]$

$$
-1.37 * \mathrm{AB}[1]+0.033 * \mathrm{AB}[2]
$$

Flexural Strength $=+8.07-0.55 * \mathrm{~A}-0.37 * \mathrm{~B}[1]+0.100 * \mathrm{~B}[2]$

$$
-0.35 * \mathrm{AB}[1]+0.15 * \mathrm{AB}[2]
$$

Model summary statistics give several comparative measures for model selection [Design-Expert software 2014; Kockal and Ozturan 2011; Kockal 2015]. The above equations are based on the quadratic model for density and 2 factor interactions (2FI) for compressive strength and flexural strength suggested by the software against other models such as linear and cubic since these models fitted well with the experimental data.

Analysis of variance (ANOVA) are given in Tables 2-4. From the F test, it was found that the calculated F value was more than the tabulated $\mathrm{F}$ value for the corresponding degrees of freedom thus rejecting the null hypothesis of "significant lack of fit" for linear, 2FI and quadratic models indicating that the lack of fit is insignificant. Quadratic being the higher order polynomial was selected among them for density and $2 \mathrm{FI}$ models for compressive and flexural strength. ANOVA for response surface model gives the sum of squares and degrees of freedom for the model terms from which mean square of the model terms are calculated. $\mathrm{F}$ value of the models and individual model terms help in finding their significance. The model $\mathrm{F}$ values of 166.05, 14.38 and 35.15 imply that the models are significant. Values of "Prob > F" less than 0.0500 indicate significant model terms. 
Table 2. ANOVA for Density Response Surface Quadratic Model

\begin{tabular}{|c|c|c|c|c|c|}
\hline Source & Sum of & $\mathrm{df}$ & Mean & $\mathrm{F}$ & p-value \\
\hline Model & 0.039 & 6 & $6.457 \mathrm{E}-003$ & 166.05 & 0.0060 \\
\hline A-Percentage & 0.018 & 1 & 0.018 & 466.71 & 0.0021 \\
\hline B-Aggregate type & 0.011 & 2 & $5.344 \mathrm{E}-003$ & 137.43 & 0.0072 \\
\hline $\mathrm{AB}$ & $7.900 \mathrm{E}-003$ & 2 & $3.950 \mathrm{E}-003$ & 101.57 & 0.0097 \\
\hline $\mathrm{A}^{2}$ & $2.006 \mathrm{E}-003$ & 1 & $2.006 \mathrm{E}-003$ & 51.57 & 0.0188 \\
\hline Residual & $7.778 \mathrm{E}-005$ & 2 & $3.889 \mathrm{E}-005$ & - & - \\
\hline Cor Total & 0.039 & 8 & - & - & - \\
\hline Std. Dev. & \multicolumn{2}{|l|}{$6.236 \mathrm{E}-003$} & \multicolumn{2}{|l|}{ R-Squared } & 0.9980 \\
\hline Mean & \multicolumn{2}{|l|}{2.02} & \multicolumn{2}{|c|}{ Adj R-Squared } & 0.9920 \\
\hline C.V. \% & \multicolumn{2}{|l|}{0.31} & \multicolumn{2}{|c|}{ Pred R-Squared } & 0.9391 \\
\hline PRESS & \multicolumn{2}{|l|}{ 2.362E-003 } & \multicolumn{2}{|c|}{ Adeq Precision } & 38.184 \\
\hline
\end{tabular}

Table 3. ANOVA for Compressive Strength Response Surface 2FI Model

\begin{tabular}{|c|c|c|c|c|c|}
\hline Source & $\begin{array}{l}\text { Sum of } \\
\text { Caneمسم }\end{array}$ & $\mathrm{df}$ & 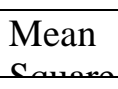 & $\begin{array}{l}\text { F } \\
\text { Foll }\end{array}$ & $\begin{array}{l}\text { p-value } \\
D \text { D }\end{array}$ \\
\hline Model & 42.51 & 5 & 8.50 & 14.38 & 0.0262 \\
\hline A-Percentage & 20.17 & 1 & 20.17 & 34.12 & 0.0100 \\
\hline B-Aggregate type & 15.05 & 2 & 7.52 & 12.73 & 0.0342 \\
\hline $\mathrm{AB}$ & 7.29 & 2 & 3.65 & 6.17 & 0.0865 \\
\hline Residual & 1.77 & 3 & 0.59 & - & - \\
\hline Cor Total & 44.28 & 8 & - & - & - \\
\hline Std. Dev. & \multicolumn{2}{|l|}{0.77} & \multicolumn{2}{|c|}{ R-Squared } & 0.9600 \\
\hline Mean & \multicolumn{2}{|l|}{41.77} & \multicolumn{2}{|c|}{ Adj R-Squared } & 0.8932 \\
\hline C.V. $\%$ & \multicolumn{2}{|l|}{1.84} & \multicolumn{2}{|c|}{ Pred R-Squared } & 0.4593 \\
\hline PRESS & \multicolumn{2}{|l|}{23.94} & \multicolumn{2}{|c|}{ Adeq Precision } & 11.098 \\
\hline
\end{tabular}

Figure 1-3 exhibit predicted versus actual values of responses. Plots of experimental and theoretical values indicated an excellent fit for density, compressive strength and flexural strength. RSM demonstrated that experimental values were reasonably close to the predicted values confirming the validity and adequacy of the predicted models. Among the different models studied, for density, only the quadratic model was found to fit the experimental data best with standard deviation of $6.236 \mathrm{E}-003$ and with correlation coefficient $\left(\mathrm{R}^{2}\right.$ value) of 0.998 , respectively. The large $\mathrm{R}^{2}$ values were evidences for the good relationships which proved that there was no remarkable variations between the experimental and estimated values [Kockal and Ozturan 2011]. 
Table 4. ANOVA for Flexural Strength Response Surface 2FI Model

\begin{tabular}{|c|c|c|c|c|c|}
\hline Source & Sum of & $\mathrm{df}$ & Mean & $\mathrm{F}$ & $\mathrm{p}$-value \\
\hline Model & 2.83 & 5 & 0.57 & 35.15 & 0.0073 \\
\hline A- & 1.81 & 1 & 1.81 & 112.66 & 0.0018 \\
\hline B- & 0.65 & 2 & 0.32 & 20.07 & 0.0183 \\
\hline $\mathrm{AB}$ & 0.37 & 2 & 0.18 & 11.48 & 0.0393 \\
\hline Residual & 0.048 & 3 & 0.016 & - & - \\
\hline Cor Total & 2.88 & 8 & - & - & - \\
\hline Std. Dev. & \multicolumn{2}{|l|}{0.13} & \multicolumn{2}{|c|}{ R-Squared } & 0.9832 \\
\hline Mean & \multicolumn{2}{|l|}{8.07} & \multicolumn{2}{|c|}{ Adj R-Squared } & 0.9552 \\
\hline C.V. \% & \multicolumn{2}{|l|}{1.57} & \multicolumn{2}{|c|}{ Pred R-Squared } & 0.7734 \\
\hline PRESS & \multicolumn{2}{|l|}{0.65} & \multicolumn{2}{|c|}{ Adeq Precision } & 18.172 \\
\hline
\end{tabular}

However, for compressive and flexural strength, 2 factor interactions (2FI) were found to fit the experimental data best with a standard deviations of 0.77 and 0.13 with a correlation coefficients $\left(\mathrm{R}^{2}\right.$ value $)$ of 0.96 and 0.9832 indicating that the fitnesses of the selected models are good and the models could be used for further navigations. The results demonstrated that the models developed are quite accurate as the percentages of error in prediction were in a good agreement.

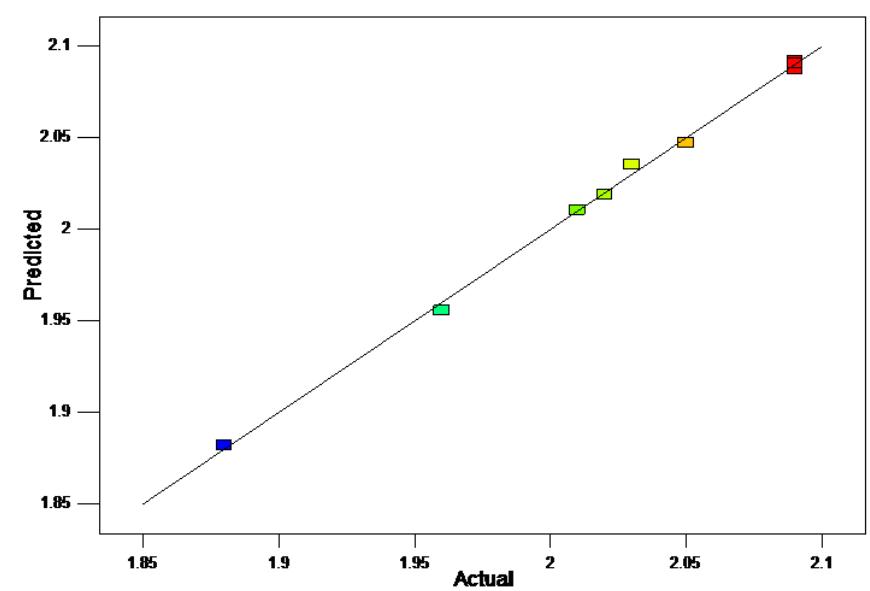

Figure 1. Predicted vs Actual Values of Density

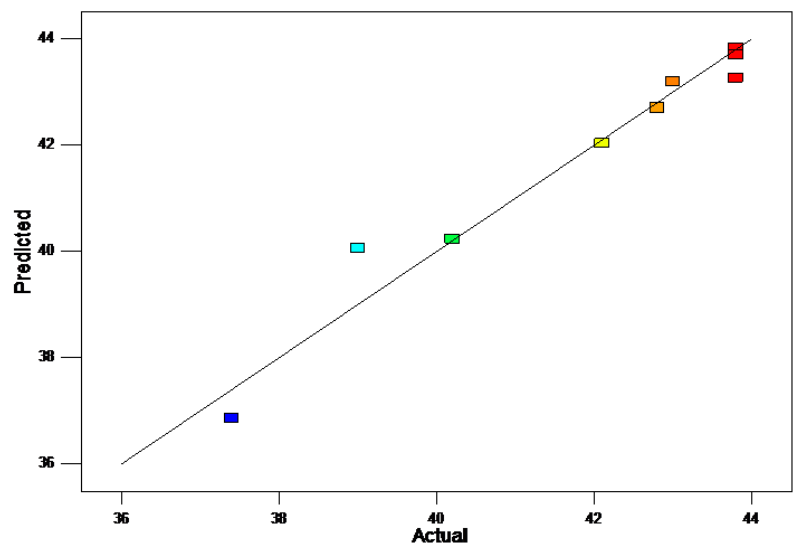

Figure 2. Predicted vs Actual Values of Compressive Strength (MPa) 


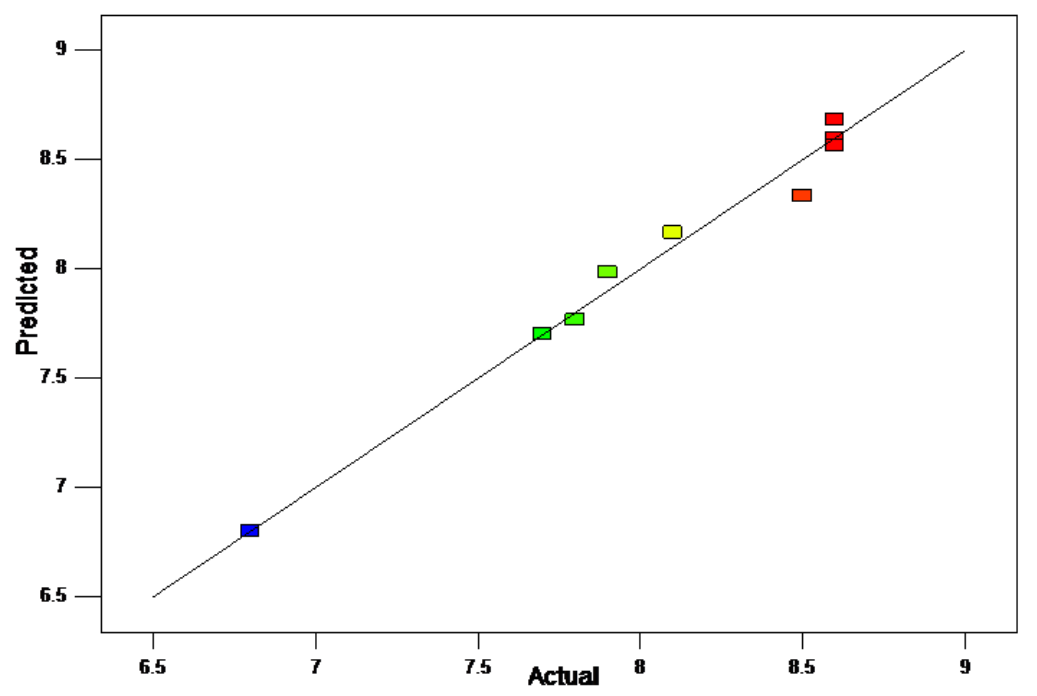

Figure 3. Predicted vs Actual Values of Flexural Strength (MPa)

As can be seen from the ANOVA results for the density, compressive and flexural strength, all the adequacy measures are in logical agreement and indicate significant relationships. The adequate precision ratios in all cases are greater than 4 which indicate adequate models discrimination. For the density model, the results indicated that the main effect of the waste content and type and the quadratic effect of the content and type along with the interaction effect of the content and type were significant model terms. In compressive strength model, the analysis of variance results demonstrated that the main effect of the waste content and type were significant model terms. However, the interaction effect of the content and waste type was the factor that had insignificant effect on compressive strength. The analysis of variance result for the flexural strength model showed that the main effect of the waste content and type along with the interaction effect of the content and waste type were significant model terms.

The optimization part in Design-Expert software searches for a combination of factor levels that simultaneously satisfy the requirements placed (i.e. optimization criteria) on each one of the responses and process factors (i.e. multiple-response optimization) [Benyounis et al. 2005]. The numerical optimization process involves combining the goals into an overall desirability function. The desirability method is recommended due to its simplicity and availability in the software and provides flexibility in weighting and giving importance for individual response [Kohli and Singh 2010]. Solving such multiple response optimization problems using this technique involves using a technique for combining multiple responses into a dimensionless measure of performance called the overall desirability function. As any increase in the density is usually reflected in increasing the strength, as a consequence both strength and density are usually studied together. On balance, and based on the above discussion, it is better to run an optimization study to find out the optimal properties at which the desirable mechanical and physical properties can be achieved. In fact, once the models have been developed and checked for adequacy, the optimization criteria can be set to find out the optimum characteristics [Kockal and Ozturan 2011]. In this investigation, one criterion were implemented to achieve relatively high strength lightweight CM (Table 5). In the criterion, the goal was to reach the maximum strength and stiffness as well as the minimum density. Table 6 presents the optimal solution based on the optimization criterion as determined by design-expert software. The scale of the desirability function ranges from $\mathrm{d}=0$ which suggests that the response is completely unacceptable, and $\mathrm{d}=1$, which suggests that the response is exactly of the target value [Shanmuganatan and Kumar 2014]. The optimization results clearly demonstrated that CM containing ceramic aggregate with a value of approximately $30 \%$ content had the highest desirabilities among all others that would lead to minimum density and maximum compressive strength, flexural strength and stiffness of 2.018, 43.2 $\mathrm{MPa}, 8.3 \mathrm{MPa}$ and $28240 \mathrm{MPa}$, respectively. 
Table 5. Optimization Criterion Used In This Study

\begin{tabular}{|l|l|l|l|l|}
\hline \multirow{2}{*}{ Name } & \multicolumn{2}{|l|}{ Limits } & \multirow{2}{*}{ Importance } & Goal \\
\cline { 2 - 5 } & Lower & Upper & & is in range \\
\hline Content & 0 & 60 & 3 & is in range \\
\hline Type & Brick & Ceramic & 3 & minimize \\
\hline Density & 1.88 & 2.09 & 3 & maximize \\
\hline Compressive Strength & 37.4 & 43.8 & 3 & maximize \\
\hline Flexural Tensile Strength & 6.8 & 8.6 & 3 & maximize \\
\hline Modulus of Elasticity & 23890 & 28450 & 3 &
\end{tabular}

Table 6. Optimal Solution as Obtained by Software Based on the Criterion

\begin{tabular}{|l|l|l|l|l|l|l|l|}
\hline Number & Percentage & Aggregate & Density & Compressive & Flexural & Modulus & Desirability \\
\hline 1 & 30.639 & Ceramic & 2.018 & 43.189 & 8.326 & 28239.51 & 0.708 \\
\hline 2 & 30.275 & Ceramic & 2.019 & 43.195 & 8.330 & 28251.19 & 0.708 \\
\hline 3 & 21.239 & Marble & 2.044 & 42.559 & 8.283 & 28264.15 & 0.611 \\
\hline 4 & 14.896 & Brick & 2.016 & 41.678 & 8.153 & 26034.17 & 0.536 \\
\hline
\end{tabular}

Figure 4 shows the ramps for maximum desirability for ceramic based on the criterion. Desirability is an objective function that ranges from zero outside of the limits to one at the goal. The numerical optimization finds a point that maximizes the desirability function. For several responses and factors, all goals get combined into one desirability function [Dhiman and Verma 2012]. It is obvious that the graphical optimization allows visual selection of the optimum properties according to certain criterion. These types of desirability plots are extremely practical for quick technical use in the workshop to choose the values of the parameters that would achieve certain response value for these types of CM. The desirability decreased with decrease in waste content.

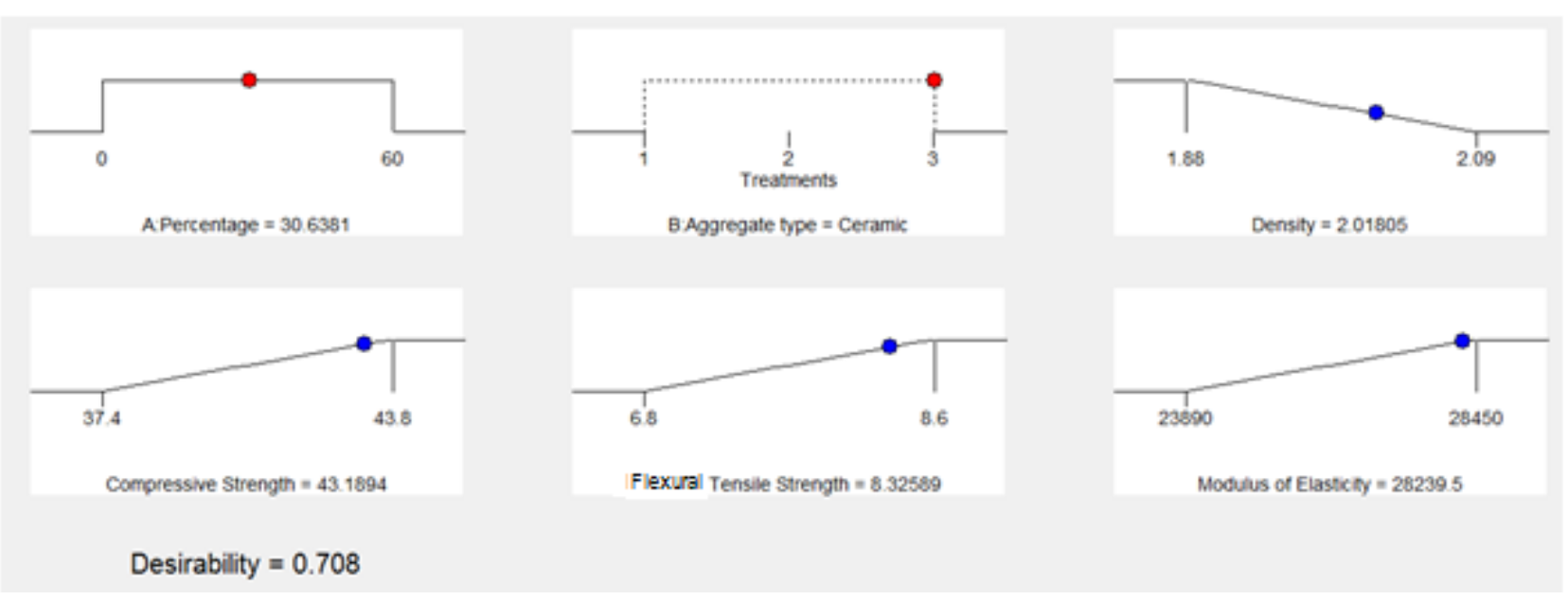

Figure 4. Ramps for Maximum Desirability 


\section{CONCLUSION}

Response surface methodology was employed to relate the aggregate input parameters (type and content) to the four responses (specific gravity, modulus of elasticity, flexural and compressive strength). The results obtained from design expert software were found to be optimal and satisfy the optimum response values. The model is compared with experimental results and the results demonstrated that the models developed were accurate as the percentages of error in prediction were in a good agreement. In contrast to the density and flexural strength, no significant interaction effect was found in the case of the compressive strength. Using software, the results were analyzed and four optimum composition having minimum density and maximum strength and modulus of elasticity were achieved. Compositions with ceramic aggregates had the highest desirability with a value of 0.708 among all others.

\section{ACKNOWLEDGEMENTS}

This work was partially supported by Akdeniz University Scientific Research Center (Project number: 2011.01.0102.009).

\section{REFERENCES}

ASTM C 39 (2000) Standard test method for compressive strength of cylindrical concrete specimens. Annual Book of ASTM Standards, West Conshohocken, PA, USA

ASTM C 469 (2002) Standard test method for static modulus of elasticity and poisson's ratio of concrete in compression. Annual Book of ASTM Standards, West Conshohocken, PA, USA

ASTM C 642 (2013) Standard test method for density, absorption, and voids in hardened concrete. American Society for Testing and Materials, Annual Book of ASTM Standards, Pennsylvania, USA

Azargohar R, Dalai AK (2005) Production of activated carbon from luscar char: experimental and modeling studies. Microporous and Mesoporous Materials 85:219-225

Benyounis KY, Olabi AG, Hashmi MSJ (2005) Optimizing the laser-welded butt joints of medium carbon steel using RSM. Journal of Materials Processing Technology 164-165:986-989

Benyounis KY, Olabi AG, Hashmi MSJ (2008) Multi-response optimization of $\mathrm{CO}_{2}$ laser-welding process of austenitic stainless steel. Optics \& Laser Technology 40:76-87

Design-Expert software User's guide (2014) Technical manual. Stat-Ease Inc., Minneapolis, MN

Dhiman S, Verma S (2012) Optimization of melt-in-mouth tablets of levocetirizine dihydrochloride using response surface methodology. International Journal of Pharmacy and Pharmaceutical Sciences 4(1):176-184

Garg SK., Manna A, Jain A (2014) An investigation on machinability of Al/10 \% $\mathrm{ZrO}_{2(\mathrm{p})}$-metal matrix composite by wedm and parametric optimization using desirability function approach. Arabian Journal for Science and Engineering 39(4):3251-3270

Kockal NU, Ozturan T (2011) Optimization of properties of fly ash aggregates for high-strength lightweight concrete production. Materials and Design 32:3586-3593

Kockal NU, Ozturan T (2011) Strength and elastic properties of structural lightweight concretes. Materials and Design 32:2396-2403

Kockal NU (2015) Optimizing production parameters of ceramic tiles incorporating fly ash using response surface methodology. Ceramics International 41(10): 14529-14536 
Kockal NU (2015) Behavior of mortars produced with construction wastes exposed to different treatments. Indian Journal of Engineering \& Materials Sciences 22(2):203-214

Kohli A, Singh H (2010) Optimizing mean effective case depth of induction hardened parts (rolled condition) using response surface methodology. International Journal on Emerging Technologies $1(1): 87-91$

Kohli A, Singh H (2011) Optimization of processing parameters in induction hardening using response surface methodology. Sadhana 3:141-152

Liyana-Pathirana C, Shahidi F (2005) Optimization of extraction of phenolic compounds from wheat using response surface methodology. Food Chemistry 93:47-56

Mannan S, Fakhru'l-Razi A, Alam MZ (2007) Optimization of process parameters for the bioconversion of activated sludge by penicillium corylophilum, using response surface methodology. Journal of Environmental Sciences 19:23-28

Mugendiran V, Gnanavelbabu A, Ramadoss R (2014) Parameter optimization for surface roughness and wall thickness on AA5052 Aluminium alloy by incremental forming using response surface methodology. Procedia Engineering 97:1991 - 2000

Muthukumar M, Mohan D, Rajendran M (2003) Optimization of mix proportions of mineral aggregates using box behnken design of experiments. Cement \& Concrete Composites 25:751-758

Ramakrishna G, Susmita M (2012) Application of response surface methodology for optimization of Cr(III) and $\mathrm{Cr}(\mathrm{VI})$ adsorption on commercial activated carbons. Research Journal of Chemical Sciences 2(2):40-48

Shanmuganatan SP, Kumar VSS (2014) Modeling of incremental forming process parameters of Al 3003 (O) by response surface methodology. Procedia Engineering 97:346 - 356

TS EN 1015-11 (1999) Methods of test for mortar for masonry. Determination of flexural and compressive strength of hardened mortar. Turkish Standard Institute, Ankara, Turkey (in Turkish)

TS EN 197-1 (2000) Cement - Part 1: Composition, specifications and conformity criteria for common cements. Turkish Standard Institute, Ankara, Turkey

TS EN 196-1 (2009) Methods of testing cement. Determination of strength. Turkish Standard Institute, Ankara, Turkey (in Turkish) 